\title{
Depression treatment patterns among individuals with osteoarthritis: a cross sectional study
}

\author{
Parul Agarwal', Xiaoyun Pan and Usha Sambamoorthi
}

\begin{abstract}
Background: Arthritis and depression often co-occur; however, studies that describe patterns of depression treatment among individuals with arthritis are scant. The purpose of the study was to examine depression treatment patterns among individuals with osteoarthritis (OA) by predisposing, enabling, need factors, personal health practices and external health environment.

Methods: Retrospective cross-sectional design was used. Data were obtained from 2008 and 2010 Medical Expenditure Panel Survey (MEPS). The sample consisted of 647adults aged over 21 years with depression and OA. Depression treatment was categorized as: 1) No treatment;2) antidepressant use only and 3) both antidepressants and psychotherapy (combination therapy). Chi- square tests and multinomial logistic regressions were used to describe patterns of depression treatment. All analysis was performed using Statistical Analysis Software (SAS) version 9.3.
\end{abstract}

Results: Overall, $13.0 \%$ of the study sample reported no depression treatment, $67.8 \%$ used antidepressants only and $19.2 \%$ used combination therapy. Among individuals with OA significant subgroup differences in depression treatment were observed. For example, African Americans were less likely to report depression treatment compared to whites [antidepressants: $\mathrm{AOR}=0.33,95 \% \mathrm{Cl}=0.21,0.51$; combination therapy: $\mathrm{AOR}=0.39,95 \% \mathrm{Cl}=0.23,0.65$ ]. Elderly adults were more likely to receive antidepressants and less likely to receive psychotherapy as compared to younger adults $[\mathrm{AOR}=0.53,95 \% \mathrm{Cl}=0.28,0.98]$. Adults with anxiety were more likely to report depression treatment compared to those without anxiety [antidepressants: $\mathrm{AOR}=1.53,95 \% \mathrm{Cl}=1.06,2.22$; combination therapy: $\mathrm{AOR}=3.52$, $95 \% \mathrm{Cl}=2.40,5.15]$.

Conclusion: Future research needs to examine the reason for low rates of combination therapy as well as subgroup differences in combination therapy among individuals with $O A$.

Keywords: Arthritis, Antidepressants, Psychotherapy, MEPS, Depression treatment

\section{Background}

Individuals with arthritis have high rates of co-occurring depression and/or anxiety [1]. Prior studies have reported negative impacts of depression on the quality of life of individuals with rheumatoid arthritis (RA), osteoarthritis (OA) and fibromyalgia [2-4]. Among individuals with arthritis, depression is associated with increased pain, work disability and functional decline [5-7]. While pain is common in individuals with arthritis [8], depression can exacerbate this problem because depression is known to independently cause pain [9]. Similarly, pain can also lead

\footnotetext{
* Correspondence: pagarwal@hsc.wvu.edu

School of Pharmacy, Department of Pharmaceutical Systems and Policy, West Virginia University, Morgantown, WV, USA
}

to depression, suggesting that the relationship between depression and pain is bi-directional [10]. Therefore, the management strategies for depression should take into account both depressive symptoms and pain [11].

Antidepressants have been found to be effective in reducing pain among individuals with $\mathrm{OA}$ and fibromyalgia $[12,13]$. Although, antidepressants therapy is the major modality of treatment for depression, it may be used to treat both depression and pain as well for individuals with arthritis $[4,13]$. For example, a randomized controlled trial (RCT) known as Stepped Care for Affective Disorders and Musculoskeletal Pain found that antidepressant therapy followed by pain self-management program resulted in

\section{Biomed Central}


improvement in depression scores and reduction in pain severity and disability [14].

Combination therapy (antidepressants with psychotherapy) is also found to be effective in treating depression [15]. American Psychiatric Association recommends combination of psychotherapy and antidepressant medication as initial treatment for individuals with moderate to severe major depressive disorder [15]. In an RCT of 681 adults with chronic major depressive disorder it was concluded that a combination of nefazodone (an antidepressant) and psychotherapy was more effective in relieving depression compared to either form of treatment alone [16]. This finding has also been substantiated among individuals with arthritis. Results from an RCT performed at 18 primary care clinics - IMPACT (Improving Mood Promoting Access to Collaborative Treatment) among 1,801 older adults with arthritis (93\% with OA) and depression, revealed that individuals who received combination therapy (antidepressants with psychotherapy) experienced not only a reduction of depressive symptoms and pain but also improvements in the functional status and quality of life compared to those who received usual depression treatment [4].

\section{Objective}

The aforementioned studies suggest that antidepressants and psychotherapy can provide relief from depression and pain among individuals with OA. However, it is not known whether findings from these clinical trials have been translated into routine clinical practices of depression care among individuals with $\mathrm{OA}$ in real-world settings. In fact, research on patterns of depression treatment among various subgroups of individuals with depression and OA is sparse. Such studies are critical for understanding subgroup differences in depression treatment as well as informing intervention efforts to promote effective depression care. Therefore, the main objective of this study was to examine patterns of depression treatment by predisposing, enabling, need factors, personal health practices and external health environment among individuals with $\mathrm{OA}$.

\section{Conceptual framework}

The basic framework for the study is the expanded behavioral model on use of health services proposed by Anderson [17]. The model posits that healthcare treatment or use is affected by: (1) each individual's unique predisposition for using services (predisposing factors), (2) the means available to each individual for obtaining services (enabling factors), and (3) each individual's level of need (need factors). Under this model predisposing variables (e.g. gender, age, and race), enabling variables (e.g. marital status, education and poverty status), need variables (e.g. health status variables and pain), personal health practices (e.g. physical activity, obesity and smoking) and external healthcare environment (e.g. metro status) affect depression treatment.

\section{Methods \\ Study design}

Retrospective cross-sectional study design was used to describe patterns of depression treatment among individuals with $\mathrm{OA}$.

\section{Data source}

Data were obtained from two years (2008 and 2010) of the Medical Expenditure Panel Survey (MEPS) dataset, which is available for public use. MEPS is a large-scale nationally representative survey of U.S. families and individuals, medical providers and employers, implemented by the Agency for Healthcare Research and Quality (AHRQ). MEPS contains information on medical conditions and mental health conditions, healthcare use services and medical and mental health treatment including prescription drugs and counseling [18]. To minimize underreporting of conditions, MEPS used extensive probes, provided the respondents with calendars, and used shorter recall period [18]. In addition, MEPS elicited information on medical and mental health conditions from medical providers. Respondents were queried whether: 1) they had been diagnosed with specific conditions, 2) the household members had experienced a medical event such as emergency visit or office visit for the condition, 3) the condition caused disability, and 4) the chronic condition bothered the respondent during a specific reference period [19]. The medical conditions reported by the household respondent were found to be consistent with data from medical care providers [20].

Information on medical and mental health conditions was collected verbatim from the household respondents. These health conditions were then converted to be consistent with the International Classification of Diseases, 9th Edition, Clinical Modification (ICD-9-CM) codes by professional coders. These ICD-9-CM codes were then converted by AHRQ into clinical classification codes [21]. Medical condition files available to the researchers contain 3-digit ICD-9-CM and clinical classification codes. For the purpose of analysis, all health conditions used in the paper were based on clinical classification codes or ICD-9-CM codes unless otherwise specified.

\section{Analytical sample}

For the current study, two years of cross-sectional data were pooled to gain an adequate sample size as recommended by MEPS designers [22]. As MEPS follows individuals for two years, data for 2008 and 2010 were used rather than two consecutive years to ensure that repeated observations from the same individual are not 
included [18]. The analytical sample consisted of adults ( $\mathrm{n}=647)$ with depression, aged 21 years or older, alive during the observation year and who reported OA. Individuals with $\mathrm{OA}$ were identified by an affirmative response to a question that queried whether the respondents have ever been diagnosed with arthritis or if they had clinical classification codes indicating arthritis in their medical conditions file. A small number of individuals who used only psychotherapy for depression treatment were excluded $(n=25)$. Individuals who reported not having any medical expenditure during the calendar year were also excluded.

\section{Measures}

\section{Dependent variable: depression treatment}

Any Antidepressant Use was identified from prescription drugs file using therapeutic class codes. The MEPS linked drug names and national drug codes to Multumlexicon classification scheme to classify prescription drugs into various therapeutic classes. These therapeutic class codes were made available to the researchers. In the current study, antidepressants were identified from the therapeutic class code 247. Individuals with one or more prescriptions for antidepressants were considered as antidepressant users.

Any Psychotherapy Use was derived from outpatient and office-based provider visits files. These files contained information on reasons for the visits. Individuals with at least one visit with the stated purpose of psychotherapy or mental health counseling were considered to receive psychotherapy [23].

Antidepressant and psychotherapy use were combined to represent combination therapy. Depression treatment was categorized into 3 groups: (1) no depression treatment, (2) antidepressant use only, (3) and psychotherapy with antidepressants (combination therapy).

\section{Independent variables}

Predisposing variables consisted of gender (women, men), race (white, African Americans, and others) and age in years grouped into 4 categories (22-39, 40-49, 50-64, 65 and above). Enabling factors consisted of marital status (married and not married), education (less than high school, high school, and above high school), poverty status (poor or near poor, middle income, and high income) and health insurance (private, public, and uninsured). Need variables included perceived physical and mental health status (excellent or very good, good, and fair or poor), functional disability (yes/no), pain (pain and no pain), and chronic conditions such as chronic obstructive pulmonary disease (COPD), diabetes, heart disease, and anxiety. Personal health practices included current smoking (current smoker, and others), physical activity (moderate to vigorous 3 times/week versus no physical activity), and body mass index (BMI) categories (under or normal, overweight, and obese). Metro status (metro versus non metro) was used to represent external healthcare environment.

\section{Pain}

Pain was included as one of the need factors because depression treatment can often be influenced by presence of pain [11]. Antidepressants are sometimes used to relieve pain among individuals with arthritis and other chronic conditions [24]. Information about pain was extracted from a question that queried the respondents whether pain interfered with their normal work outside the home and housework during the past 4 weeks. In MEPS, pain was reported on a 5-point scale: 1) Not at all, 2) A little bit, 3) Moderately, 4) Quite a bit, and 5) extremely. For purposes of this study pain was classified into two categories: 1) pain and 2) no pain. Self-reported pain from MEPS has been used in published literature to estimate cost of pain [25].

\section{Statistical analysis}

Chi-square tests were used to examine significant subgroup differences in depression treatment among individuals with OA. Multinomial logistic regressions were used to examine patterns of depression treatment by predisposing, enabling, need factors, personal health practices and external healthcare environment. The dependent variable consisted of: (1) no depression treatment, (2) antidepressant use only, and (3) psychotherapy with antidepressants (combination therapy). For the dependent variable, "no depression treatment" was used as the reference category. The parameter estimates from the regression were transformed to adjusted odds ratios (AORs) and their corresponding 95\% confidence intervals (CIs) were examined. All analyses accounted for complex survey design of MEPS with Statistical Analysis Software (SAS) version 9.3.

\section{Results}

Among individuals with $\mathrm{OA}$ and depression the majority were women $(76.0 \%)$, whites $(87.2 \%)$, and older adults above age $50(83.1 \%)$. Nearly one-third (34.4\%) were below the $100 \%-200 \%$ federal poverty line. Only $24.4 \%$ reported excellent/very good physical health and 33.5\% reported excellent/very good mental health. Anxiety was prevalent in $25.1 \%$ of the individuals with $\mathrm{OA}$ and depression. An overwhelming majority of adults with OA reported pain (87.2\%). (Data not presented in tabular form).

Table 1 presents the weighted percent of depression treatment categories by predisposing, enabling, need factors, personal health practices and external health environment. Except for few variables (gender, poverty 
Table 1 Weighted percent of depression treatment among individuals with depression and osteoarthritis: medical expenditure panel survey, 2008 and 2010

\begin{tabular}{|c|c|c|c|c|}
\hline & No treatment & Antidepressants only & Antidepressants \& psychotherapy & sig \\
\hline & Wt. (\%) & Wt. (\%) & Wt. (\%) & \\
\hline \multirow[t]{2}{*}{ ALL } & 13.0 & 67.8 & 19.2 & \\
\hline & & disposing factors & & \\
\hline
\end{tabular}

Gender

$\begin{array}{llll}\text { Female } & 11.9 & 68.1 & 20.0 \\ \text { Men } & 16.8 & 66.7 & 16.5\end{array}$

Race

$\begin{array}{ll}\text { White } & 11.1 \\ \text { African Americans } & 27.8 \\ \text { Other race } & 25.2\end{array}$

Age groups

$\begin{array}{ll}22-39 & 16.4 \\ 40-49 & 12.2 \\ 50-64 & 12.1 \\ 65,+ & 14.2\end{array}$

Marital status

\section{Enabling factors}

$\begin{array}{ll}\text { Married } & 11.1 \\ \text { Not married } & 15.2\end{array}$

Education

Less than high school

High school

More than high school

Poverty Status

$\begin{array}{ll}\text { Poor } & 13.7 \\ \text { Middle income } & 15.1\end{array}$

High income

Insurance

Private

Public

Uninsured

Perceived physical health
Excellent/very good
Good
Fair/poor

Perceived mental health

$\begin{array}{ll}\text { Excellent/very good } & 12.2 \\ \text { Good } & 11.9 \\ \text { Fair/poor } & 15.1\end{array}$

Anxiety

$$
\text { Anxiety }
$$

No anxiety
Need factors 
Table 1 Weighted percent of depression treatment among individuals with depression and osteoarthritis: medical expenditure panel survey, 2008 and 2010 (Continued)

Pain

$\begin{array}{lllr}\text { Pain } & 11.7 & 68.3 & 19.9 \\ \text { No pain at all } & 20.7 & 62.0 & 17.4\end{array}$

COPD

$\begin{array}{lccr}\text { COPD } & 9.4 & 67.4 & 23.2 \\ \text { No COPD } & 14.7 & 67.9 & 17.3\end{array}$

Diabetes

$\begin{array}{lccr}\text { Diabetes } & 8.7 & 72.4 & 18.8 \\ \text { No diabetes } & 14.4 & 66.3 & 19.3\end{array}$

Heart disease

$\begin{array}{ll}\text { Heart } & 10.4 \\ \text { No heart } & 14.2\end{array}$

$10.4 \quad 74.4 \quad 15.2$

Functional disability

Yes

$65.3 \quad 16.9$

Personal health practice factors

BMI

$\begin{array}{llll}\text { Under-normal weight } & 15.6 & 74.3 & 10.1 \\ \text { Overweight } & 15.3 & 63.5 & 21.2 \\ \text { Obese } & 10.7 & 66.8 & 22.5 \\ & & & 27.9 \\ \text { Current smoker } & 11.7 & 60.3 & 17.2 \\ \text { Other } & 13.2 & 69.5 & \end{array}$

Exercise

3 times per week
No exercise

No exercise

14.7

11.9

External healthcare environment

\section{.9}


OA are summarized in Table 2. Among individuals with OA, African Americans were significantly less likely to use antidepressants as compared to whites $(\mathrm{AOR}=0.33$, $95 \% \mathrm{CI}=0.21,0.51$ ); they were also less likely to use combination therapy $(\mathrm{AOR}=0.39,95 \% \mathrm{CI}=0.23,0.65)$. Individuals with anxiety were more likely to use antidepressants only and combination therapy. Individuals with anxiety were almost 3 times $(\mathrm{AOR}=3.52 ; 95 \% \mathrm{CI}=2.40,5.15)$ as likely as those without anxiety to report using combination therapy; they were more likely to use antidepressants only $(\mathrm{AOR}=1.53,95 \% \mathrm{CI}=1.06,2.22)$ compared to those without anxiety.

Elderly individuals with OA (age 65 and older) were more likely to use antidepressants only $(\mathrm{AOR}=2.19$, $95 \% \mathrm{CI}=1.40,3.43)$ compared to younger adults in the age group 22-39 years. However, they were less likely to receive combination therapy $(\mathrm{AOR}=0.53,95 \% \mathrm{CI}=0.28$, $0.98)$ compared to younger adults. Similarly, adults with fair or poor perceived mental health were more likely to receive combination therapy $(\mathrm{AOR}=1.93,95 \% \mathrm{CI}=1.15$, 3.25) compared to those with excellent or very good perceived mental health. However, they were less likely to receive antidepressants only $(\mathrm{AOR}=0.64,95 \% \mathrm{CI}=0.45$, 0.92) compared to those with excellent or very good or good perceived mental health.

Women with OA were more likely to use antidepressants only as compared to men $(\mathrm{AOR}=1.67,95 \% \mathrm{CI}=$ $1.28,2.18)$. Significant differences were not observed between genders for combination therapy. Adults with chronic conditions such as diabetes $(\mathrm{AOR}=1.64,95 \%$ $\mathrm{CI} 1.20,2.25)$ and heart disease $(\mathrm{AOR}=1.49,95 \% \mathrm{CI}=$ $1.07,2.09)$ were more likely to receive antidepressants only compared to those without diabetes or heart disease. Again, statistically significant associations were not observed between combination therapy and type of chronic conditions. Adults with obesity were more likely to receive combination therapy $(\mathrm{AOR}=1.51,95 \% \mathrm{CI}=1.01,2.25)$ compared to those with underweight/normal BMI category. However, no significant differences were observed for antidepressants use only between BMI categories.

\section{Discussion}

The current study set out to examine patterns of depression treatment among individuals with $\mathrm{OA}$ and depression using a nationally representative data on non-institutionalized civilian US population. In the study sample of adults with OA, $13.0 \%$ did not receive any treatment for depression and $87 \%$ reported antidepressant use (either alone or as combination therapy). The rate of depression treatment found in this study was higher than that reported elsewhere. For example, a study that examined the patterns of depression treatment trends from 1998 through 2007 among all adults reported an antidepressant use of $75.3 \%$ in 2007 [26].
However, the results cannot be directly compared due to differences in study population and time period.

Approximately, one in five individuals with $\mathrm{OA}$ and depression used combination therapy for depression treatment. Given the beneficial effect of combination therapy to provide relief from depressive symptoms as well as pain one would expect a higher percentage of individuals with arthritis to be treated with combination therapy. Future research needs to address the barriers to combination therapy for depression care in this population. However, the rate of psychotherapy use found in this study is consistent with published literature in which $24 \%$ individuals used psychotherapy in 2005 from office-based psychiatrists [27]. On the contrary, another study that analyzed national trends in outpatient psychotherapy found lower rates of psychotherapy use estimated to be $10.5 \%$ in 2007 [28]. Rate of psychotherapy use in the study sample may not be directly comparable as the treatment group included both antidepressants and psychotherapy.

While this study did not analyze the reasons for no treatment, it is evident from other studies that cost, side effects, severity of depression, stigma, patient-provider relationship, lack of previous family history of depression, fear of referral to the psychiatrist are barriers to depression treatment $[29,30]$. It is also plausible individuals with OA may rely on alternative and complementary therapies such as yoga that have been found to be effective in treating depression [31] and therefore, this study may have over-estimated rate of non-treatment.

Although evidence supports the use of antidepressants for pain among individuals with major chronic pain conditions [24], an interesting finding in this study was the absence of a relationship between pain and antidepressants use in both bivariate and multivariate models. Absence of the relationship between pain and antidepressant use needs to be interpreted with caution because of a very small sample size of adults without pain.

The study findings with respect to racial disparities in depression treatment among individuals with $\mathrm{OA}$ are consistent with the existing literature. For example, African Americans were less likely to receive antidepressants and combination therapy for depression compared to whites. Existing studies have suggested that African Americans were less likely to accept antidepressants and counseling as compared to other racial/ethnic subgroups due to socio economic status, access to care and patient preferences [32-34].

This study found greater likelihood of antidepressants use and lower likelihood of psychotherapy among elderly compared to younger adults. These findings are consistent with evidence from published literature that suggests an association between increasing age and decreasing odds of receiving psychotherapy [35,36]. As mentioned 
Table 2 Adjusted odds ratios and 95\% confidence intervals from multinomial logistic regression on depression treatment among individuals with depression and osteoarthritis: medical expenditures panel survey, 2008 and 2010

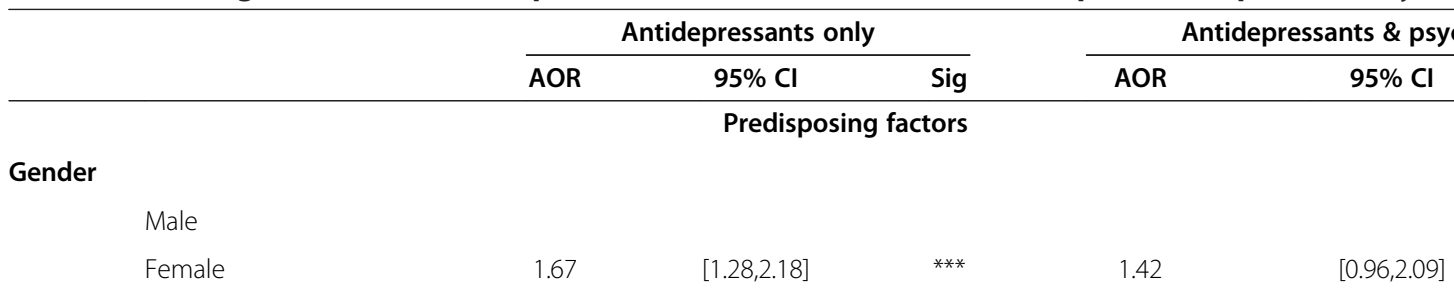

Race

$$
\text { White }
$$

African Americans

Other race

$\begin{array}{ll}0.33 & {[0.21,0.51]} \\ 0.39 & {[0.26,0.58]}\end{array}$

Age

$$
\begin{aligned}
& 22-39 \\
& 40-49 \\
& 50-64 \\
& 65,+
\end{aligned}
$$

$\begin{array}{ll}* * * & 0.39 \\ * * * & 0.60\end{array}$

Marital status

Married
Not married

Education

$$
\begin{aligned}
& \text { High school } \\
& \text { Less than high school }
\end{aligned}
$$

More than high school

$\begin{array}{ll}0.68 & {[0.45,1.04]} \\ 0.89 & {[0.64,1.22]}\end{array}$

Poverty status

0.71

$[0.54,0.95]$

1.60
2.24
2.19

$[1.09,2.34]$
$[1.46,3.42]$
$[1.40,3.43]$

\section{Enabling factors}

1.01

1.27

1.43

0.53

$\begin{array}{ll}* & 1.27 \\ * * & 1.43 \\ * * & 0.53\end{array}$

$[0.82,1.98]$

$[0.90,2.26]$

[0.28,0.98]

\section{High income}

Poor

Middle income

0.76

$[0.53,1.10]$

0.52

[0.32,0.82]

Insurance

$$
\begin{aligned}
& \text { Private } \\
& \text { Public }
\end{aligned}
$$

Uninsured

Need factors

Perceived mental health

Excellent/very good

Good

MH Fair/poor

Anxiety

$$
\begin{aligned}
& \text { No anxiety } \\
& \text { Anxiety }
\end{aligned}
$$

Perceived physical health

Excellent/very good

Good
Fair/poor


Table 2 Adjusted odds ratios and $95 \%$ confidence intervals from multinomial logistic regression on depression treatment among individuals with depression and osteoarthritis: medical expenditures panel survey, 2008 and 2010 (Continued)

Pain
No pain at all
Pain

COPD

\author{
No COPD \\ COPD
}

Diabetes

\author{
No diabetes \\ Diabetes
}

1.64

$[1.20,2.25]$

**

1.34

$[0.90,2.01]$

Heart disease

No heart disease
Heart disease

Functional disability

No

Yes

0.99

$[0.73,1.34]$

1.39

$[0.94,2.05]$

BMI

Personal health practice factors

Under-normal weight

Overweight
Obese

$\begin{array}{ll}1.08 & {[0.77,1.53]} \\ 1.31 & {[0.92,1.87]}\end{array}$

status

Other

Current smoker

1.15

$[0.77,1.72]$

1.21

$[0.81,1.81]$

Exercise

3 times per week

No exercise

0.92

[0.69,1.22]

0.94

$[0.65,1.36]$

External healthcare environment

Metro
Metro
Rural

Note: Based on 647 adults, aged 21 years older with self-reported depression and Osteoarthritis who were alive during the calendar year (2008 and 2010). Asterisks represent significant group differences by type of treatment compared to the reference group based on multinomial logistic regression. The reference group for the dependent variable in the multinomial logistic regression was "No Depression Treatment".

AOR: Adjusted odds ratio; $\mathrm{Cl}$ : Confidence Interval; Sig: significance.

${ }^{* * *} \mathrm{p}<.001 ;{ }^{* *} .001 \leq \mathrm{p}<.01 ; * .01 \leq \mathrm{p}<.05$.

in the introduction combination therapy has been found to be effective in reducing pain and improving depressive symptoms among older adults [4]. Given the beneficial effects of combination therapy for the elderly, the study findings suggest that current depression care may not be optimal for elderly with OA. While this study did not explore the reasons for lower rates of psychotherapy among elderly with OA, it can be speculated that elderly may not receive psychotherapy due to access barriers in the form of high co-payments related to psychotherapy
[37] or cognitive impairment [36]. Future studies are needed to explore reasons for low uptake of combination therapy so that interventions can be tailored to promote optimal therapy for depression care among elderly with depression and OA.

In this study combination therapy for depression was more likely in individuals with anxiety compared to individuals with depression and without anxiety. It is well documented that anxiety often co-occurs with depression in adults with arthritis [1]. In this study, 
nearly $25 \%$ of individuals with OA and depression also reported anxiety disorders. Although treatment for comorbid depression and anxiety differ by the type of anxiety disorder, cognitive-behavioral therapy (CBT), has well-documented efficacy for both depression and anxiety disorders [38].

The statistically significant association between obesity and combination therapy is also worth noting. Obesity and depression have bi-directional relationship and they often occur together [39], however, there have been no studies on combination therapy among individuals with obesity and depression. In a pilot study it was documented that individuals who were provided CBT for depression along with evidence-based behavioral treatment for obesity achieved a clinically significant reduction in depressive symptoms in 16 weeks [40]. Therefore, it is plausible that those with obesity and depression may receive treatments that combine psychotherapy for depression to achieve better clinical outcomes.

Findings from this study need to be interpreted in the light of its strengths and limitations. Strengths include a nationally representative survey, availability of a comprehensive list of variables that may be associated with depression treatment. Furthermore, prescription drug and psychotherapy information allowed us to categorize no depression treatment as well as type of depression treatment. However, there are some limitations. All measures were self-reported and subject to recall bias. Only general psychotherapy was measured and distinctions between types of psychotherapies could not be used, which may be important in determining appropriate care. Patient preferences and use of alternative and complementary medicine for depression treatment were not included. Therefore, the study could not identify the reasons for lack of depression treatment among individuals with OA.

\section{Conclusions}

Despite these limitations, this study added to the emerging nascent literature on depression treatment patterns among individuals with chronic physical conditions, specifically OA. It also highlighted many subgroup differences in likelihood of treatment and type of depression treatment. Although combination therapy is proven effective among individuals with $\mathrm{OA}$, some subgroups such as the elderly and those with chronic illnesses (example: diabetes and heart disease) did not report receiving combination therapy. Future research needs to evaluate barriers to depression care among African Americans and challenges to combination therapy for some subgroups of adults with OA. In addition, further studies need to be conducted as to whether lack of depression treatment is associated with poor health outcomes such as functional status among those with OA.

\section{Abbreviations}

RA: Rheumatoid arthritis; OA: Osteoarthritis; IMPACT: Improving Mood Promoting Access to Collaborative Treatment; COPD: Chronic obstructive pulmonary disease; MEPS: Medical Expenditure Panel Survey; AHRQ: Agency for Healthcare Research and Quality; ICD-9-CM: International Classification of Diseases, 9th Edition, Clinical Modification; BMI: Body mass index.

\section{Competing interests}

The views expressed in this academic research paper are those of the authors and do not reflect the official policy or position of West Virginia University (WVU) or any other affiliated organizations.

\section{Authors' contributions}

1) PA reviewed the literature, facilitated data management, work on data analysis, drafted the manuscript and incorporated suggestions from co-authors in successive iterations. 2) XP advised on data analysis, interpreted findings and provided input on successive iterations of the manuscript. 3) US designed the study, supervised data analysis, interpreted findings and provided input on successive iterations of the manuscript. All authors read and approved the final version of the manuscript.

\section{Acknowledgement}

The authors would also like to thank Ms. Kathryn Flack, MPH for her support and suggestions.

This research was conducted under the auspices of West Virginia Collaborative Health Outcomes Research of Therapies and Services (WV CoHORTS) Center, in which Dr. Sambamoorthi is the Director of the Data Repository Core.

Received: 5 November 2012 Accepted: 9 April 2013

Published: 22 April 2013

\section{References}

1. Murphy LB, Sacks JJ, Brady TJ, Hootman JM, Chapman DP: Anxiety and depression among US adults with arthritis: prevalence and correlates. Arthritis Care Res 2012, 64(7):968-976. Epub 2012/05/03.

2. Tander B, Cengiz K, Alayli G, Ilhanli I, Canbaz S, Canturk F: A comparative evaluation of health related quality of life and depression in patients with fibromyalgia syndrome and rheumatoid arthritis. Rheumatol Int 2008, 28(9):859-865. Epub 2008/03/05.

3. Lempp H, Ibrahim F, Shaw T, Hofmann D, Graves H, Thornicroft G, et al: Comparative quality of life in patients with depression and rheumatoid arthritis. Int Rev Psychiatry 2011, 23(1):118-124. Epub 2011/02/23.

4. Lin EH, Katon W, Von Korff M, Tang L, Williams JW Jr, Kroenke K, et al: Effect of improving depression care on pain and functional outcomes among older adults with arthritis: a randomized controlled trial. JAMA 2003, 290(18):2428-2429. Epub 2003/11/13.

5. Dickens C, Creed F: The burden of depression in patients with rheumatoid arthritis. Rheumatology 2001, 40(12):1327.

6. Lowe B, Willand L, Eich W, Zipfel S, Ho AD, Herzog W, et al: Psychiatric comorbidity and work disability in patients with inflammatory rheumatic diseases. Psychosom Med 2004, 66(3):395.

7. Dunlop DD, Semanik P, Song J, Manheim LM, Shih V, Chang RW: Risk factors for functional decline in older adults with arthritis. Arthritis Rheum 2005, 52(4):1274-1282.

8. Bolen J, Schieb L, Hootman JM, Helmick CG, Theis K, Murphy LB, et al: Differences in the prevalence and severity of arthritis among racial/ ethnic groups in the United States, National Health Interview Survey, 2002, 2003, and 2006. Prev Chronic Dis 2010, 7(3):A64. Epub 2010/04/17.

9. Katona C, Peveler R, Dowrick C, Wessely S, Feinmann C, Gask L, et al: Pain symptoms in depression: definition and clinical significance. Clin Med 2005, 5(4):390-395. Epub 2005/09/06.

10. Kroenke K, Wu J, Bair MJ, Krebs EE, Damush TM, Tu W: Reciprocal relationship between pain and depression: a 12-month longitudinal analysis in primary care. J Pain 2011, 12(9):964-973.

11. Trivedi MH: The link between depression and physical symptoms. Prim Care Companion J Clin Psychiatry 2004, 6(Suppl 1):12-16.

12. Chappell AS, Ossanna MJ, Liu-Seifert H, lyengar S, Skljarevski V, Li LC, et al: Duloxetine, a centrally acting analgesic, in the treatment of patients with osteoarthritis knee pain: a 13-week, randomized, placebocontrolled trial. Pain 2009, 146(3):253-260. Epub 2009/07/25. 
13. Branco JC, Zachrisson O, Perrot S, Mainguy Y: A European multicenter randomized double-blind placebo-controlled monotherapy clinical trial of milnacipran in treatment of fibromyalgia. J Rheumatol 2010, 37(4):851-859. Epub 2010/02/17.

14. Kroenke K, Bair MJ, Damush TM, Wu J, Hoke S, Sutherland J, et al: Optimized antidepressant therapy and pain self-management in primary care patients with depression and musculoskeletal pain: a randomized controlled trial. JAMA 2009, 301(20):2099-2110. Epub 2009/05/28.

15. Gelenberg AJ: Practice Guidelines for the Treatment of Patients With Major Depressive Disorder. American Psychiatric Association; 2010. Available from: http://psychiatryonline.org/content.aspx?bookid=28\&sectionid=1667485.

16. Keller MB, McCullough JP, Klein DN, Arnow B, Dunner DL, Gelenberg AJ, et al: A comparison of nefazodone, the cognitive behavioral-analysis system of psychotherapy, and their combination for the treatment of chronic depression. New England J Med 2000, 342(20):1462-1470. Epub 2000/05/18.

17. Andersen RM: Revisiting the behavioral model and access to medical care: does it matter? J Heal Soc Behav 1995, 36(1):1-10. Epub 1995/03/01.

18. AHRQ: MEPS-HC Sample Design and Collection Process. Rockville: AHRQ [cited 2011 17th February]; Available from: http://www.meps.ahrq.gov/ mepsweb/survey comp/hc data_collection.jsp.

19. AHRQ: MEPS HC-121: 2008 Full Year Consolidated Data File. Center for Financing, Access, and Cost Trends540. Gaither RoadRockville, MD. 20850: Agency for Healthcare Research and Quality; 2010 [cited 2012 9th August]; Available from: http://meps.ahrq.gov/mepsweb/data_stats/download_data/ pufs/h121/h121doc.shtml.

20. Machlin S, Cohen J, Elixhauser A, Beauregard K, Steiner C: Sensitivity of household reported medical conditions in the medical expenditure panel survey. Med Care 2009, 47(6):618-625. Epub 2009/05/13.

21. AHRQ: MEPS HC-120: 2008 Medical Conditions. Center for Financing, Access, and Cost Trends540. Gaither RoadRockville, MD: Agency for Healthcare Research and Quality; 2010. cited 2012 9th August]; Available from: http://meps.ahra. gov/mepsweb/data_stats/download_data/pufs/h120/h120doc.shtml.

22. Sommers J: An Examination of State Estimates Using Multiple Years of Data from the Medical Expenditure Panel Survey, Household Component. Agency for Healthcare Research and Quality Working Paper No. 06004; 2006. Available from: http://meps.ahrq.gov/mepsweb/data_files/publications/ workingpapers/wp_06004.pdf.

23. Harman JS, Edlund MJ, Fortney JC, Kallas H: The influence of comorbid chronic medical conditions on the adequacy of depression care for older Americans. J Am Geriatr Soc 2005, 53(12):2178-2183.

24. Verdu B, Decosterd I, Buclin T, Stiefel F, Berney A: Antidepressants for the treatment of chronic pain. Drugs 2008, 68(18):2611-2632. Epub 2008/12/20.

25. Gaskin DJ, Richard P: The economic costs of pain in the United States. The J Pain 2012, 13(8):715-724. Epub 2012/05/23.

26. Marcus SC, Olfson M: National trends in the treatment for depression from 1998 to 2007. Arch Gen Psychiatry 2010, 67(12):1265-1273.

27. Mojtabai R, Olfson M: National trends in psychotherapy by office-based psychiatrists. Arch Gen Psychiatry 2008, 65(8):962-970. Epub 2008/08/06

28. Olfson M, Marcus SC: National trends in outpatient psychotherapy. Am J Psychiatry 2010, 167(12):1456-1463. Epub 2010/08/06.

29. Nutting PA, Rost K, Dickinson M, Werner JJ, Dickinson P, Smith JL, et al: Barriers to initiating depression treatment in primary care practice. J Gen Int Med 2002, 17(2):103-111. Epub 2002/02/14.

30. Simon GE, Fleck M, Lucas R, Bushnell DM: Prevalence and predictors of depression treatment in an international primary care study. Am J Psychiatry 2004, 16(9):1626-1634. Epub 2004/09/01.

31. Cabral P, Meyer HB, Ames D: Effectiveness of yoga therapy as a complementary treatment for major psychiatric disorders: a metaanalysis. Prim Care companion CNS disorders 2011, 13(4): . Epub 2011/12/02.

32. Cooper LA, Gonzales JJ, Gallo JJ, Rost KM, Meredith LS, Rubenstein LV, et al: The acceptability of treatment for depression among African-American, Hispanic, and white primary care patients. Med Care 2003, 41(4):479-489 Epub 2003/04/01.

33. Simpson SM, Krishnan LL, Kunik ME, Ruiz P: Racial disparities in diagnosis and treatment of depression: a literature review. Psychiatr Q 2007, 78(1):3-14. Epub 2006/11/15.

34. Givens JL, Houston TK, Van Voorhees BW, Ford DE, Cooper LA: Ethnicity and preferences for depression treatment. Gen Hosp Psychiatry 2007, 29(3):182-191. Epub 2007/05/09.
35. Akincigil A, Olfson M, Walkup JT, Siegel MJ, Kalay E, Amin S, et al: Diagnosis and treatment of depression in older community-dwelling adults: 1992-2005. J Am Geriatr Soc 2011, 59(6):1042-1051. Epub 2011/06/09.

36. Harman JS, Edlund MJ, Fortney JC: Disparities in the adequacy of depression treatment in the United States. Psychiatr Serv 2004, 55(12):1379-1385. Epub 2004/12/02.

37. Simon GE, Grothaus L, Durham ML, VonKorff M, Pabiniak C: Impact of visit copayments on outpatient mental health utilization by members of a health maintenance organization. Am J Psychiatry 1996, 153(3):331-338.

38. Butler AC, Chapman JE, Forman EM, Beck AT: The empirical status of cognitive-behavioral therapy: a review of meta-analyses. Clin Psychol Rev 2006, 26(1):17-31. Epub 2005/10/04

39. Simon GE, Ludman EJ, Linde JA, Operskalski BH, Ichikawa L, Rohde $P$, et al: Association between obesity and depression in middle-aged women. Gen Hosp Psychiatry 2008, 30(1):32-39.

40. Faulconbridge LF, Wadden TA, Berkowitz RI, Pulcini ME, Treadwell T: Treatment of comorbid obesity and major depressive disorder: a prospective pilot study for their combined treatment. J Obes 2011, 2011:870385.

doi:10.1186/1471-244X-13-121

Cite this article as: Agarwal et al:: Depression treatment patterns among individuals with osteoarthritis: a cross sectional study. BMC Psychiatry 2013 13:121.

\section{Submit your next manuscript to BioMed Central and take full advantage of:}

- Convenient online submission

- Thorough peer review

- No space constraints or color figure charges

- Immediate publication on acceptance

- Inclusion in PubMed, CAS, Scopus and Google Scholar

- Research which is freely available for redistribution

Submit your manuscript at www.biomedcentral.com/submit
C BioMed Central 